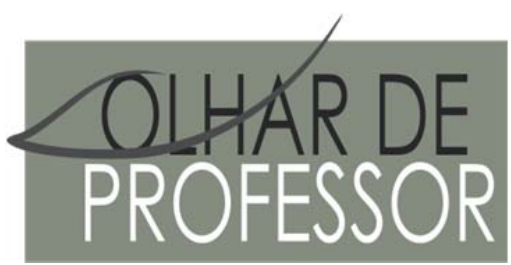

DOI: 10.5212/OLHARPROFR.V.211.0008

\title{
O DESENVOLVIMENTO DE ASPECTOS ESPECÍFICOS DA APRENDIZAGEM EM GEOMETRIA SEGUNDO RAYMOND DUVAL: UMA ARTICULAÇÃO COM O AMBIENTE DINÂMICO GEOGEBRA ${ }^{1}$
}

\section{THE DEVELOPMENT OF SPECIFIC ASPECTS OF GEOMETRY LEARNING ACCORDING TO RAYMOND DUVAL: AN ARTICULATION WITH THE GEOGEBRA DYNAMIC ENVIRONMENT \\ EL DESARROLLO DE ASPECTOS ESPECIÍFICOS DEL APRENDIZAJE EN GEOMETRÍA SEGÚN RAYMOND DUVAL: UNA ARTICULACIÓN CON EL AMBIENTE DINÁMICO GEOGEBRA}

\author{
BRANDT, CELIA FINCK \\ MORETTI, MÉRICLES THADEU* \\ FRANCIELE ISABELITA LOPES NOVAK ${ }^{\text {*** }}$
}

\begin{abstract}
Resumo: Esse trabalho é oriundo de uma pesquisa qualitativa de mestrado que articulou o GeoGebra às considerações de Raymond Duval sobre processos cognitivos específicos para o desenvolvimento do pensamento geométrico. O presente estudo trata das apreensões e da desconstrução dimensional. A mobilização das apreensões e da desconstrução dimensional estarão presentes em atividades desenvolvidas nesse ambiente dinâmico? A partir desse questionamento, esse trabalho visa indicar resultados de duas atividades de uma sequência didática envolvendo a Geometria que foram aplicadas à trinta alunos do oitavo ano do Ensino Fundamental de uma escola pública do estado do Paraná. Dentre os apontamentos, as atividades apresentadas mostram potencialidades para a apreensão operatória em que as modificações ótica e posicional são mobilizadas de maneira simultânea.
\end{abstract}

Palavras-chave: Geometria. Apreensões. Desconstrução dimensional. GeoGebra.

Abstract: This paper stems from a qualitative master's research that articulated GeoGebra to Raymond Duval's considerations on specific cognitive processes for the development of geometric thinking. The present study deals with apprehensions and dimensional deconstruction. Will the mobilization of apprehensions and dimensional deconstruction be present in activities developed in this dynamic environment? From this questioning, this work aims to indicate the results of two activities of a didactic sequence involving Geometry that were applied to thirty students of the eighth grade of Elementary School of a public school in the state of Paraná. Among the results, the activities presented show potentialities for the operative apprehension in which the optical and positional modifications are simultaneously mobilized.

\footnotetext{
${ }^{1}$ Artigo elaborado a partir da dissertação de Mestrado de autoria de Franciele Isabelita Lopes Novak sob a orientação da Dra Celia Finck Brandt da UEPG em 2018. Pesquisa financiada pela Capes.

* Doutora em Educação Científica e Tecnológica pela Universidade Federal de Santa Catarina. Professora adjunta na Universidade Estadual de Ponta Grossa. E-mail: brandt@bighost.com.br

** Doutor em Didática da Matemática pelo Université de Strasbourg, França. Professor titular da Universidade Federal de Santa Catarina. E-mail: mthmoretti@gmail.com

*** Mestre em Educação pela Universidade Estadual de Ponta Grossa. Professora de Matemática no Colégio Alfa Plus em Ponta Grossa. E-mail: franciele.isa@hotmail.com
} 
Keywords: Geometry, Apprehensions, Dimensional Deconstruction, GeoGebra..

Resumen: Este trabajo es oriundo de una investigación cualitativa de maestría que articuló el GeoGebra a las consideraciones de Raymond Duval sobre procesos cognitivos específicos para el desarrollo del pensamiento geométrico. El presente estudio trata de las aprehensiones y la deconstrucción dimensional. ¿La movilización de las aprehensiones y de la deconstrucción dimensional estarán presentes en actividades desarrolladas en ese ambiente dinámico? A partir de ese cuestionamiento, ese trabajo busca indicar resultados de dos actividades de una secuencia didáctica envolviendo la Geometría que fueron aplicadas a 30 alumnos del octavo año de la Enseñanza Fundamental de una escuela pública del estado de Paraná. Entre los apuntes, las actividades presentadas muestran potencialidades para la aprehensión operatoria en que las modificaciones ópticas y posicional se movilizan de manera simultánea..

Palabras clave: Geometría, Aprehensiones, Desconstrucción Dimensional, GeoGebra..

\section{INTRODUÇÃO}

Esse artigo apresenta resultados de uma pesquisa qualitativa caracterizada como um estudo de caso relativa à um trabalho com a Geometria aliada ao ambiente dinâmico GeoGebra. É nesse campo da Matemática, a geometria, que "o aluno desenvolve um tipo especial de pensamento que lhe permite compreender, descrever e representar, de forma organizada, o mundo em que vive.” (BRASIL, 1998, p. 51). Lorenzato (1995, p. 06) complementa ainda que "aqueles que procuram um facilitador de processos mentais, encontrarão na Geometria o que precisam: prestigiando o processo de construção do conhecimento, a Geometria valoriza o descobrir, o conjecturar e o experimentar.”

A pesquisa contempla um estudo que se volta para o desenvolvimento do pensamento geométrico e, para tanto, contou com subsídios teóricos apresentados por Raymond Duval (2004, 2005, 2011, 2012a, 2012b). Esse autor relata a presença de diferentes atividades cognitivas necessárias para a aprendizagem desse campo da Matemática dentre os quais o desenvolvimento: de apreensões (perceptiva, operatória, discursiva e sequencial), de olhares (botanista, agrimensor, construtor e inventor) e da desconstrução dimensional (OD $\rightarrow 1 \mathrm{D}, 0 \mathrm{D} \rightarrow 2 \mathrm{D}, 0 \mathrm{D} \rightarrow 3 \mathrm{D}, 1 \mathrm{D} \rightarrow 0 \mathrm{D}, 2 \mathrm{D} \rightarrow 3 \mathrm{D}, 2 \mathrm{D}$ $\rightarrow 0 \mathrm{D}, 2 \mathrm{D} \rightarrow 3 \mathrm{D}, 3 \mathrm{D} \rightarrow 0 \mathrm{D}, 3 \mathrm{D} \rightarrow 1 \mathrm{D}, 3 \mathrm{D} \rightarrow 2 \mathrm{D})$. O referido estudo contemplou a organização de atividades que foram propostas a alunos da educação básica, séries finais do ensino fundamental, de uma escola pública de Ponta Grossa com foco no desenvolvimento das apreensões, olhares e desconstrução dimensional.

Para o desenvolvimento desse estudo, um olhar sobre os recursos tecnológicos, em especial, o GEOGEBRA, cuja característica é ser considerado um ambiente dinâmico de aprendizagem, foi lançado a fim de verificar que possibilidades são oferecidas para o trabalho com a Geometria. Gravina et al. (2010, p. 38) definem esses recursos como sendo "ferramentas que oferecem régua e compasso virtuais, permitindo a construção de figuras geométricas a partir das propriedades que as definem.” Dentre possibilidades verificadas, o GEOGEBRA permite a exploração das figuras ao arrastá-las, modificá-las ou reordená-las por meio do mouse,o que se revelou um ponto positivo em relação à figura geométrica estática, em que ações como as mencionadas podem ser feitas, mas com um custo de tempo elevado.A partir desses pressupostos, compreendeu-seque a articulação com o ambiente dinâmico GeoGebra seria pertinente. O que se buscou com o estudo foi responder ao seguinte questionamento: Que atividades podem ser desenvolvidas em um ambiente dinâmico de modo a promover a mobilização das operaçõ9es cognitivas das apreensões, olhares e da desconstrução dimensional?

Para o desenvolvimento do estudo foram organizadas duas atividades, compreendendo uma sequência didática, aplicadas à trinta alunos do oitavo ano do Ensino Fundamental de uma escola pública do estado do Paraná.Essas atividades envolveram a construção, visualização e conjecturas sobre polígonos e poliedros. À luz dos pressupostos de Raymond Duval, são revelados particularidades envolvendo o uso do ambiente dinâmico GeoGebra, suas potencialidades e desafios. 


\section{A GEOMETRIA SEGUNDO AS CONSIDERAÇÕES DE RAYMOND DUVAL}

Os pressupostos de Raymond Duval a respeito da Geometria indicam que é uma área da Matemática exigente, pois mobiliza tanto o olhar, quanto a linguagem e o gesto. (DUVAL, 2005). A Geometria depende da coordenação simultânea de tratamento de dois tipos de Registros de Representação Semiótica: o registro discursivo, em língua natural e o registro figural.

Os tratamentos figurais são "operações que podem ser efetuadas materialmente ou mentalmente sobre [...] uma figura geométrica, para obter uma modificação figural desta figura.” (DUVAL, 2012b, p. 287). Esses tratamentos caracterizam uma atividade cognitiva que permite, em relação à figura, "a possibilidade de modificação que surge da relação das partes com o todo, por exemplo, relações ópticas (visuais) ou posicionais de uma figura.” (DUVAL, 2004, p. 162, tradução nossa).

O registro discursivo, por sua vez, é feito em língua natural, o qual enuncia definições, teoremas ou hipóteses sobre um problema matemático, enquanto que o registro figural é necessário para evidenciar propriedades que estão contidas num determinado desenho. (DUVAL, 2004). Essa relação entre esses dois tipos de registros é notada pelo fato de uma figura permitir abordagens conceituais diversas. A fim de promover esclarecimentos sobre qual objeto matemático se trata, é indispensável que se tenha uma enunciação discursiva, ou seja, "não há desenho sem legenda.” (DUVAL, 2004, p. 168, tradução nossa).

Duval (2004) pontua que uma figura geométrica possui valores dimensionais e qualitativos. As unidades figurais elementares são qualitativas em relação ao formato, por exemplo, linhas retas ou curvas, contornos abertos ou fechados. Os valores dimensionais referem-se à dimensão 0 (0D) quando se trata de pontos, a dimensão 1 (1D) corresponde às retas ou arcos, a dimensão 2 (2D) aos polígonos e ângulos e a dimensão 3 (3D) se refere aos volumes.

Um exemplo em que se pode analisar tanto os valores dimensionais quanto qualitativos seria considerar que um triângulo é uma figura que possui contornos fechados por semirretas que se encontram em três pontos não colineares. Essas seriam as características qualitativas. Ainda em relação ao triângulo, ao analisar seus valores dimensionais se compreende que é uma figura de dimensão 2 (2D) pois é formado pela união de segmentos de retas compostos a partir de três pontos não colineares pertencentes a um mesmo plano. É possível afirmar ainda, que os segmentos de reta que fazem parte do seu contorno possuem a dimensão 1 (1D) e os três pontos de intercessão dos segmentos de reta que formam o triângulo possuem a dimensão 0 (0D).

Por meio da figura 4, a seguir, uma classificação de unidades figurais elementares que constituem uma figura geométrica é apresentada:

Figura 1: Classificação das unidades figurais elementares

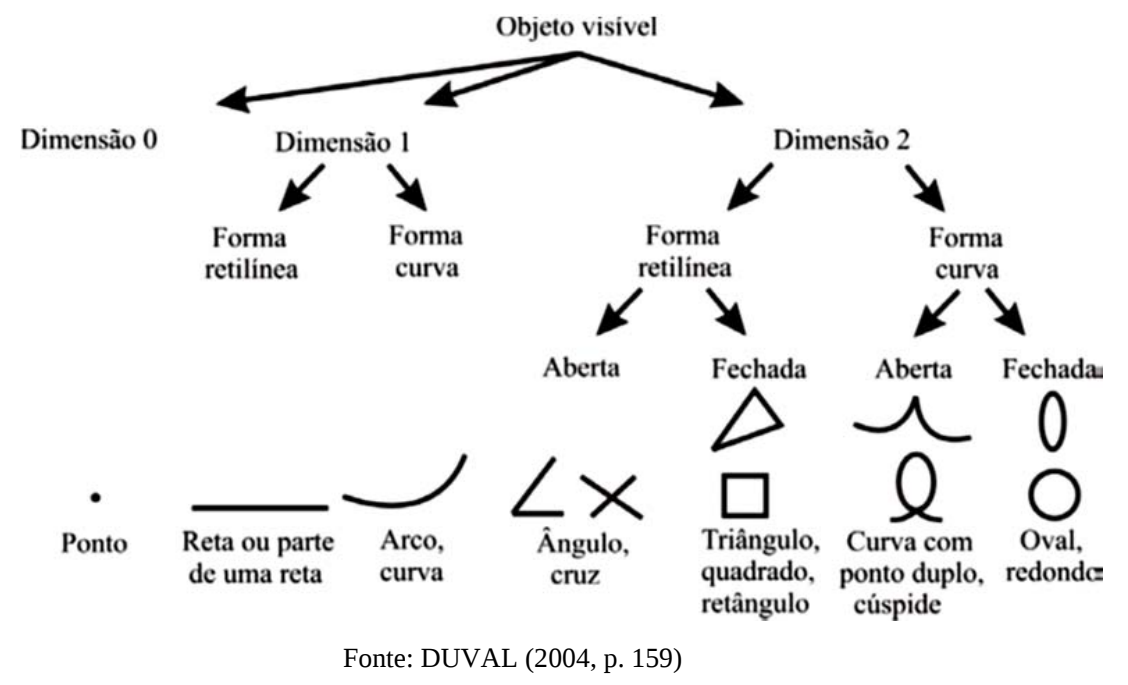


Nesta classificação se destacam as diferentes variações que uma figura geométrica pode apresentar. Quanto à variação qualitativa, os formatos retilíneo ou curvo e quanto à variação dimensional a dimensão 0 (0D) relacionada aos pontos, a dimensão 1 (1D) às retas ou arcos, a dimensão 2 (2D) aos polígonos e ângulos.A visualização de uma figura geométrica deve contemplar, segundo Duval (2011, p. 87, grifos do autor), a “[...] desconstrução dimensional das formas que reconhecemos imediatamente em outras formas que não enxergamos à primeira vista, e isso sem que nada mude na figura afixada no monitor ou construída no papel.” Esta mudança de olhar é um salto cognitivo considerável, pois é contrária ao reconhecimento automático das formas, em que a unidade figural da dimensão superior se impõe de modo imediato à percepção. (DUVAL, 2011).

Desse modo, a desconstrução dimensional refere-se ao reconhecimento das unidades figurativas de menor dimensão. Duval (2005, p. 20, tradução nossa) salienta que a desconstrução dimensional é a “[...] maneira matemática de ver” uma figura geométrica.

Duval (2005, p. 20, tradução nossa) cita como exemplo sobre essa atividade cognitiva, que se trata deum modo matemático de ver um poliedro, por exemplo, ao mencionar que,

[...] a figura de um cubo ou uma pirâmide (3D / 2D) é decomposta em uma configuração de quadrados, triângulos, etc. (unidades figurativas 2D / 2D). E os polígonos são, por sua vez, divididos em segmentos retos (unidades figurativas 1D / 2D). E as linhas, ou segmentos, podem ser divididas em pontos (Unidades 0D / 2D).

O entendimento de propriedades geométricas se dá por meio da desconstrução dimensional. Retomando o exemplo do triângulo, quando se menciona que essa figura é formada pela união de três pontos não colineares pertencentes a um mesmo plano, por meio de segmentos de reta é requisitada a desconstrução dimensional de 2D $\rightarrow 0 \mathrm{D} \rightarrow 1 \mathrm{D}$.

Além da desconstrução dimensional há também outras atividades cognitivas responsáveis pela compreensão das representações em Geometria, chamadas de apreensões.

As apreensões são distinguidas em quatro tipos: a apreensão perceptiva, a apreensão operatória, a apreensão discursiva e a apreensão sequencial. As apreensões perceptiva e operatória segundo Duval (2004) são dois níveis de compreensão das figuras geométricas que estão vinculadas com os tratamentos figurais. Esses níveis correspondem à interpretação de uma figura geométrica no que diz respeito à seleção de alternativas que serão suscetíveis para conduzir à solução de um problema proposto.

Na apreensão perceptiva, há o "reconhecimento das diferentes unidades figurais que são discerníveis em uma figura dada.” (DUVAL, 2004, p. 162, tradução nossa). Ela é considerada como o primeiro nível de apreensão das figuras geométricas, pois "uma figura é uma organização de elementos de um campo perceptivo, não homogêneo, que constitui um objeto que se destaca deste campo.” (DUVAL, 2012a, p. 121). Trata-se do reconhecimento imediato e automático das características de uma figura. Considerando a análise das variações qualitativas e dimensionais, a apreensão perceptiva permite também a interpretação da forma que uma figura está organizada.

A figura 2 mostra três desenhos:

Figura 2: Exemplos de diferentes organizações perceptivas das figuras

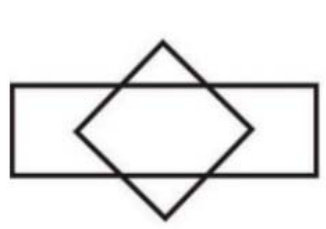

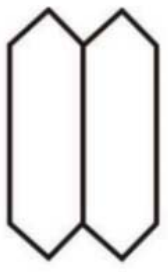

b

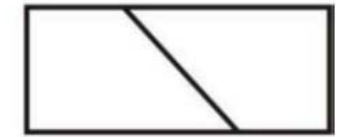

Fonte: DUVAL (2012a, p. 121) 
Para Duval (2012a), por meio da apreensão perceptiva, a Figura2a é resultado da superposição entre um retângulo e um quadrado, a Figura $2 b$ imediatamente faz verificar que são duas formas iguais com um lado em comum, enquanto a Figura 2c mostra um retângulo dividido em duas partes. Isso caracteriza o que Duval (2012a) expressa o fato de que a apreensão perceptiva é uma atividade imediata e automática em que uma figura destaca características independentemente do enunciado.

Duval (2011) comenta que, ao considerar a mudança na maneira de ver uma figura, que contemple a desconstrução dimensional, esta contraria a percepção imediata de uma figura. Por exemplo, a figura 2a pode ser formada por dois triângulos, dois pentágonos e um hexágono justapostos. Essas organizações perceptivas das figuras geométricas suscitam o outro nível de apreensão, chamado de apreensão operatória.

A apreensão operatória é uma atividade cognitiva "[...] centrada nas modificações possíveis de uma figura inicial e nas reorganizações possíveis destas modificações.” (DUVAL, 2012a, p. 125). Essa apreensão faz parte do processo heurístico de uma figura, "de descoberta da resolução do problema." (MORETTI; BRANDT, 2015, p. 604). Essa apreensão distingue-se em três diferentes modos de modificação de uma figura, chamados de: modificação mereológica, modificação ótica ou modificação de posição.

Quanto à modificação mereológica, Duval (2004) estabelece que é um tipo de tratamento em que uma figura é decomposta em subfiguras de mesma dimensão; essas subfiguras podem ser homogêneas, de mesmo formato, ou heterogêneas, cujas subfiguras podem possuir formatos diferentes. Duval (2004, p. 170, tradução nossa) explica que as “[...] subfiguras são reorganizações perceptivas diferentes que representam algumas (ou todas) as unidades figurais elementares da figura de partida."

Pelas figuras 3a e 3b é possível verificar a modificação mereológica:

Figura 3: Modificação mereológica homogênea e heterogênea em figuras geométricas
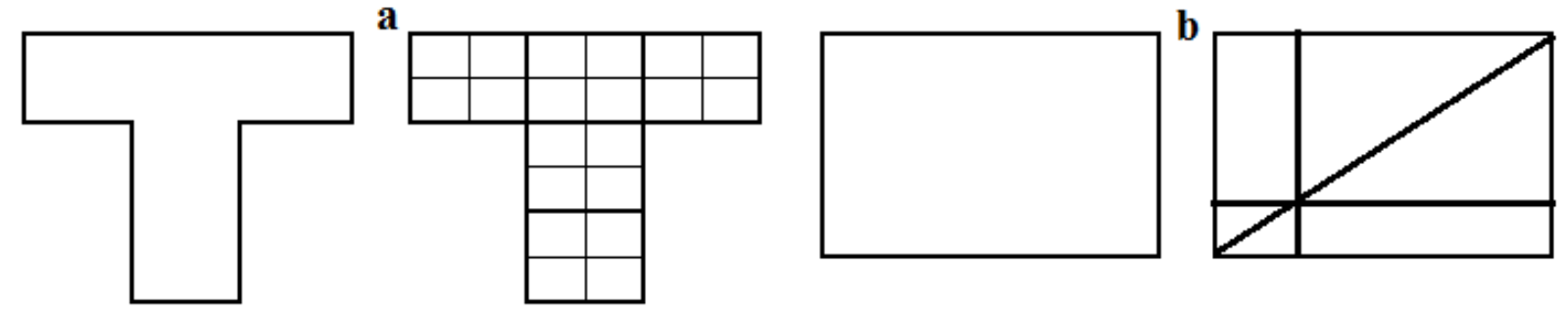

Fonte: Adaptado de DUVAL (2004, p. 165)

Na primeira figura há uma modificação mereológica homogênea, pois as subfiguras são todas do mesmo formato. A figura b é um retângulo que foi decomposto de maneira heterogênea por subfiguras com formatos diferentes, triangulares, retangulares e quadrangulares.

A próxima modificação, denominada modificação ótica segundo Duval (2012b) representa a variação de tamanho de uma mesma figura, conservando a forma e orientação no plano fronto paralelo. É uma modificação que “consiste em ver em profundidade”. (DUVAL, 2004, p. 166).

A figura 4 a seguir exemplifica esta modificação: 
Figura 4: Modificação ótica em um quadrado

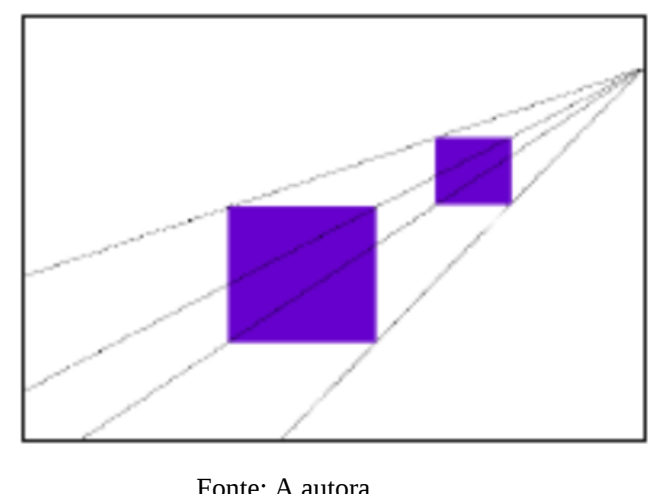

Esta modificação possui como potencialidade facilitar conceitos como o de homotetia. Duval (2004, p. 167, tradução nossa) comenta que a modificação ótica, "ao permitir uma percepção em profundidade de uma representação plana, constitui a produtividade heurística do registro figural em relação com o discurso matemático tão útil para a compreensão da homotetia.”

O terceiro tipo de modificação, denominado modificação de posição, é aquele em que na figura se conservam o tamanho e a forma, porém, ocorre a variação de orientação: rotação ou translação. (DUVAL, 2012b).

A Figura 5, a seguir, apresenta um modelo deste tipo de modificação::

Figura 5: Modificação posicional com variação de orientação

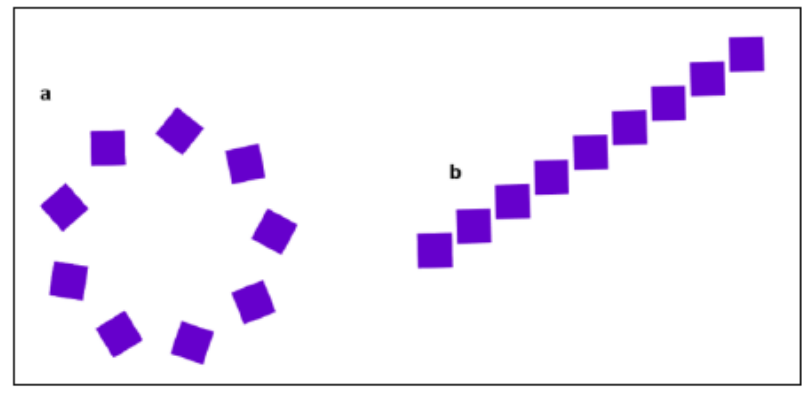

Fonte: As autoras

Essas três diferentes maneiras de decompor uma figura geométrica permitem que as mesmas cumpram a função de suporte intuitivo favorecendo a interpretação das atividades de geometria. De acordo com Duval, (2004, p. 170, tradução nossa), “O êxito da exploração de uma figura no âmbito de um problema proposto, vai depender então da articulação entre esta apreensão operatória da figura e um manejo discursivo de inferências que mobiliza uma rede de definições e de teoremas.”

A apreensão operatória neutraliza a apreensão perceptiva espontânea de uma figura. Dependendo do número, heterogeneidade e das posições das unidades figurais que compõem a figura ocorrerá um custo de tempo para a efetivação desta apreensão. (DUVAL, 2004).

Outra apreensão, denominada de sequencial, segundo Duval (2012a, p. 120), “é explicitamente solicitada em atividades de construção ou em atividades de descrição, tendo por objetivo a reprodução de uma dada figura." Trata-se do seguimento de uma lista de instruções para uma construção geométrica. Um exemplo, dado por Novak (2018, p. 42-43) se refere à construção da mediatriz de um segmento de reta, por meio de compasso e régua, em que se apresenta as seguintes instruções:

1. Construa um segmento $\overline{A B}$ com comprimento de $5 \mathrm{~cm}$.

2. Com a ponta seca do compasso no ponto A, abra uma medida maior que a metade do segmento $\overline{A B}$ e trace um arco que intersecte (corte) o segmento $\overline{A B}$. 
3. Repita o processo, mas agora pelo ponto $B$, utilizando a mesma medida de abertura do compasso.

4. Trace a mediatriz unindo as intersecções dos dois arcos.

De acordo com a Figura 6, a seguir, o resultado da sequência dos cinco passos de construção é apresentado:

Figura 6: Construção esperada a partir do seguimento das instruções de construção

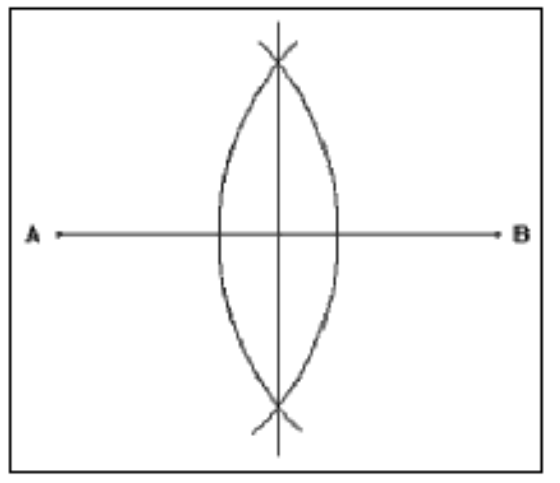

Fonte: Novak, 2018, p. 43

A apreensão sequencial se difere da apreensão discursiva pois ela não se trata de um enunciado em que há um problema a ser resolvido. A apreensão discursiva consiste em compreender os elementos da construção geométrica em que o enunciado, por meio das hipóteses, determina quais pressupostos teóricos serão úteis para a resolução do problema proposto.

A apreensão sequencial é muito importante e também precisa ser explorada no ensino. Um exemplo a respeito de que essa apreensão não é imediata pode ser visualizada em uma atividade realizada por Scheifer (2017) que apresenta uma atividade com foco na apreensão sequencial e os resultados apresentados por diferentes sujeitos.

Discurso do locutor durante a realização de uma dinâmica

\section{Instruções do locutor:}

1) Desenhe um círculo.

2) Dentro do círculo desenhar dois círculos menores, um do lado do outro.

3) Em cima do círculo pequeno desenhar um risco.

4) Embaixo dos dois círculos pequenos desenhar uma linha na vertical, não muito grande.

5) Embaixo da linha vertical desenhar uma meia-lua.

6) Embaixo do círculo desenhar um retângulo arredondado.

7) Em baixo do retângulo, desenhar um retângulo bem grande.

8) Do lado esquerdo desenhar um retângulo arredondado. E outro igual do lado direito.

9) Embaixo do retângulo grande faz um retângulo arredondado, na vertical.

10) Desenhe um igual do lado direito do retângulo

11) Em baixo de cada retângulo desenha um triângulo.

12) Dentro do retângulo grande desenha quatro círculos na vertical. 
Figura 6a. Resultados apresentados para a atividade proposta.

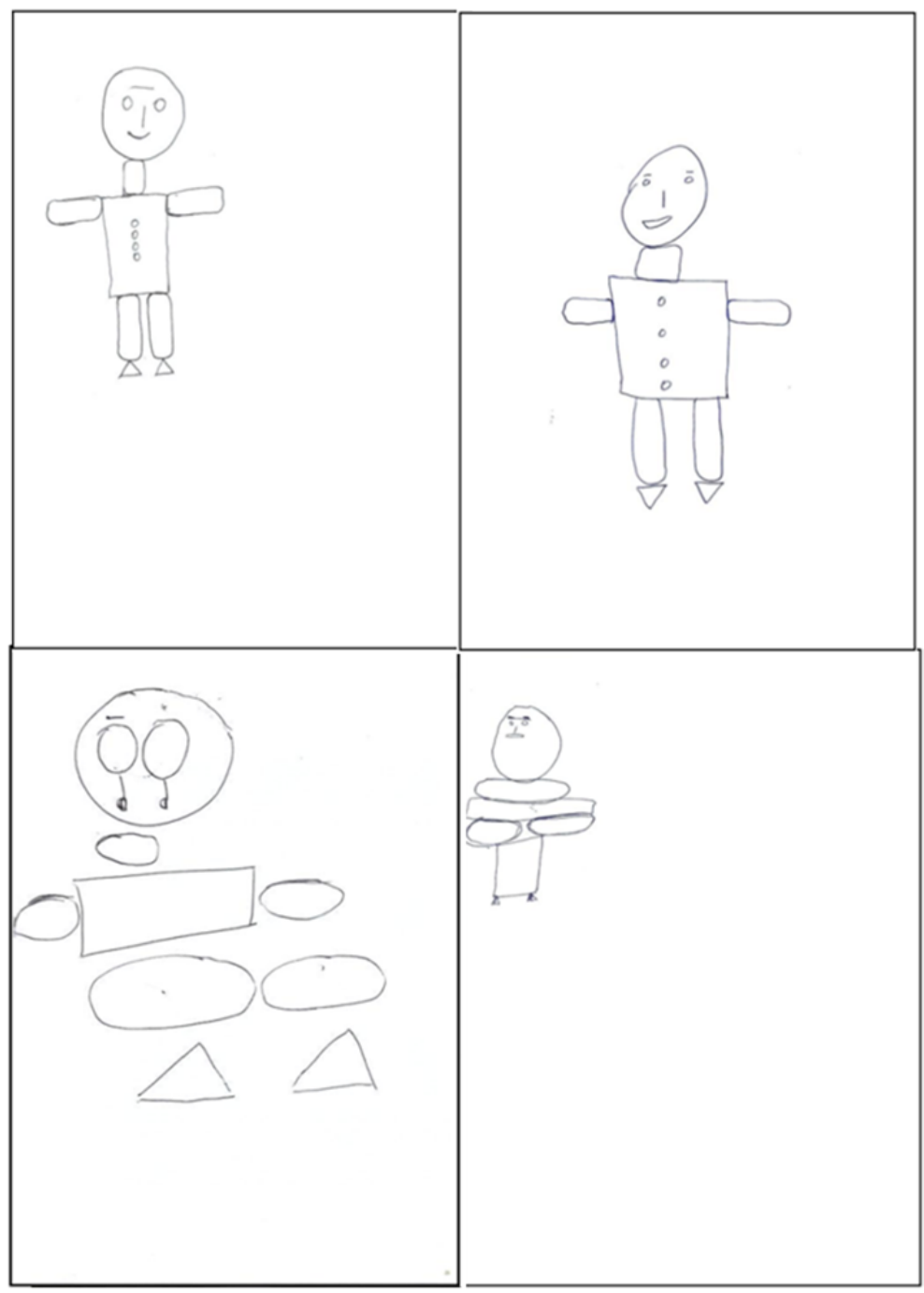

Fonte: Scheifer (2017)

No exemplo dado na figura 7 da página a seguir, uma questão extraída de um livro didático, menciona no enunciado valores para determinados ângulos.

Figura 7: Exemplo de questão que mobiliza a apreensão discursiva

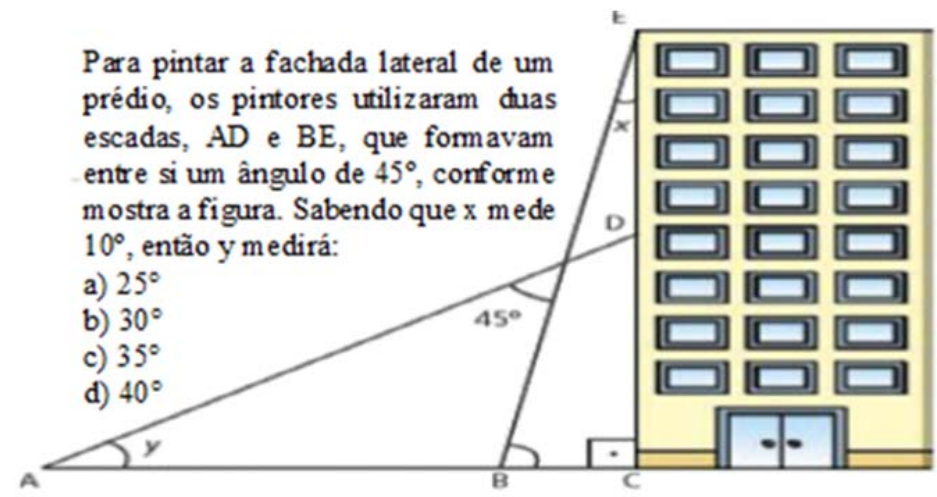

Fonte: Adaptado pelas autoras de Andrini e Vasconcelos (2012, p. 262)

Essa atividade solicita para a resolução, propriedades envolvendo a soma de ângulos internos de polígonos. 
Na resolução de um problema de Geometria é possível que as quatro apreensões - perceptiva, operatória, sequencial e discursiva - sejam necessárias, sendo que algumas dessas apreensões serão mais requisitadas que outras.

Existe também a necessidade do desenvolvimento dos olhares, que segundo Duval são fundamentais para o sucesso na resolução de problemas de geometria. A nosso ver devem ser, portanto objeto do ensino por parte do professor. Eles são resumidos no quadro 1::

Quadro 1: apreensões e olhares em geometria

\begin{tabular}{|c|c|c|c|}
\hline \multicolumn{4}{|c|}{ Apreensões } \\
\hline Perceptiva & Discursiva & Operatória & Sequencial \\
\hline \multirow{2}{*}{ É o reconhecimento de } & É a interpretação dos & São as possíveis & \\
formas, sendo imediata & elementos da figura, & podem açontes que & \\
e automática. & apresentada pelo & uma figura e as & É a construção \\
& enunciado. & reorganizações & passo a passo. \\
& & perceptivas que as & \\
& & mudanças operam. & \\
\hline
\end{tabular}

\begin{tabular}{|c|c|c|c|}
\hline \multicolumn{4}{|c|}{ Olhares } \\
\hline Icônico & \multicolumn{2}{c|}{ Não-icônico } \\
\hline Botanista & Agrimensor & Construtor & Inventor \\
\hline Permite reconhecer o & & & É o acréscimo de traços \\
contorno de formas e \\
diferenciá-las. Observar \\
diferenças nas figuras \\
$\begin{array}{c}\text { nemelhantes e } \\
\text { nem um } \\
\text { semelhanças nas formas } \\
\text { diferentes. }\end{array}$ & $\begin{array}{c}\text { medida e escala, } \\
\text { transferir de uma escala } \\
\text { de grandeza à outra. }\end{array}$ & $\begin{array}{c}\text { instrumentos, régua } \\
\text { não-graduada e } \\
\text { compasso. }\end{array}$ & $\begin{array}{c}\text { problema, operação e } \\
\text { modificação para } \\
\text { descobrir um método de } \\
\text { resolução. }\end{array}$ \\
\hline
\end{tabular}

\section{A CARACTERIZAÇ̃̃O DA PESQUISA E OS PROCEDIMENTOS METODOLÓGICOS}

O estudo de caso qualitativo caracterizou essa pesquisa. Segundo Ponte (2006, p. 16) esse tipo de abordagem visa "compreender a especificidade de uma dada situação ou fenômeno, para estudar os processos e as dinâmicas da prática, com vista à sua melhoria.” Essa metodologia se aplicou ao presente trabalho, por se tratar de uma análise da produção digital e escrita em atividades de geometria aplicadas a uma turma de alunos do $8^{\circ}$ ano dos Anos Finais do Ensino Fundamental do Estado do Paraná. Os instrumentos relativos às atividades escritas e digitais foram a principal fonte de coleta de dados, além dos protocolos de construção dos sujeitos disponibilizados pelo software GeoGebra e gravações de áudio.

A inserção no campo de pesquisa foi por meio da oferta de uma Oficina de Geometria, a qual fez uso de 09 computadores disponíveis no laboratório de informática da escola. A turma de 30 alunos foi dividida em dois grupos com no máximo uma dupla por computador. O primeiro grupo de alunos (G1) contou com a participação de 09 duplas de alunos. A identificação das duplas foi estabelecida pela letra A, acompanhada de números de 1 até 9. No segundo grupo (G2) participaram 12 sujeitos, sendo 5 duplas 2 alunos que preferiram trabalhar individualmente. Para esses sujeitos, foi atribuída a letra B seguida dos números 1 até 7. 
Os conteúdos contemplados nas atividades relatadas no presente trabalho envolveram a visualização de figuras geométricas, as diferenças entre os polígonos regulares e não regulares e também poliedros regulares e não regulares.

\section{APRESENTACÃO, ANÁLISE E DISCUSSÃO DOS DADOS}

Para a interpretação dos dados obtidos, se considerou adequada a metodologia de análise de conteúdo de Bardin (2016) a partir de um procedimento dividido em três momentos: pré-análise, exploração do material e tratamento dos resultados, interpretação e inferência.

O primeiro momento, chamado de pré-análise, é composto pelos procedimentos a seguir: leitura flutuante, escolha dos documentos, formulação de hipóteses e dos objetivos, referenciação dos índices e a elaboração dos indicadores e, por fim, a preparação do material. Na leitura flutuante, optou-se pela transcrição de todas as respostas dadas pelas duplas em uma planilha de excel. Considerou-se que a fase de escolha dos documentos contemplou as produções dos alunos sejam elas digitais ou escritas. A formulação das hipóteses e objetivos foi contemplada por meio de um estudo preliminar de cada atividade à luz dos pressupostos teóricos. A referenciação dos índices e elaboração dos indicadores, bem como a preparação do material foram estabelecidos pela organização das respostas em quadros no Excel com respostas que apresentavam similitudes.

No segundo momento de análise, chamado de "exploração do material” (BARDIN, 2016, p. 131), foi realizada a sistematização dos dados em função de critérios estabelecidos. Para essa etapa, a fim de organizar os dados coletados, foi adaptado o quadro de categorias de Scheifer (2017) que contempla as especificidades de Raymond Duval sobre a Geometria. Esse quadro foi adaptado para as questões do presente estudo apresentado a seguir:

Categorias para análise e classificação das questões de geometria

\begin{tabular}{|l|l|}
\hline Indicador da atividade cognitiva & Índices \\
\hline \multirow{2}{*}{$\begin{array}{l}\text { Características da figura geométrica em } \\
\text { relação à dimensão }\end{array}$} & $\begin{array}{l}\text { Representação }\left(\frac{n D}{2 D}\right) 2 . \\
\text { O "denominador" é a consideração do espaço no qual as } \\
\text { representações são produzidas. } \\
\text { O “numerador” é a consideração do espaço referente ao objeto } \\
\text { matemático. }\end{array}$ \\
\hline \multirow{2}{*}{ Desconstrução dimensional } & $\begin{array}{l}\text { A desconstrução dimensional conduz à visualização das } \\
\text { unidades figurais exigidas pelas atividades matemáticas. }\end{array}$ \\
\hline Apreensão dos registros figurais & $\begin{array}{l}\text { Perceptiva } \\
\text { Operatória (modificações mereológicas, posicionais e óticas) }\end{array}$ \\
\hline \multirow{2}{*}{$\begin{array}{l}\text { Aiscursiva } \\
\text { narticulação das apreensões requerida }\end{array}$} & $\begin{array}{l}\text { Figura geométrica (perceptiva e discursiva) } \\
\text { Visualização (perceptiva e operatória) } \\
\text { Heurística e demonstração (perceptiva, operatória e discursiva) } \\
\text { Construção (perceptiva, discursiva e sequencial) }\end{array}$ \\
\hline
\end{tabular}

A partir dos dados empíricos à luz dos pressupostos teóricos foram feitas as inferências. Essa etapa iniciou o terceiro momento da análise.

\footnotetext{
${ }^{2}$ Neste trabalho serão consideradas as representações no plano do papel. Mas há outras formas de classificação das representações: objetos físicos que podem ser fisicamente manipulados ( $\mathrm{nD}$ / 3D), modelos de poliedros (3D / 3D), folha de papel que pode ser dobrada ou cortada (2D / 3D), retas representadas por cordas (1D / 3D). (DUVAL, 2005, p. 17).
} 
No terceiro momento da análise, foram intensificadas as reflexões e estimativas, em que o pesquisador "pode então propor inferências e adiantar interpretações a propósito dos objetivos previstos, ou que digam respeito a outras descobertas inesperadas.” (BARDIN, 2016, p. 131). Foi contemplada, nessa fase, por meio das informações fornecidas pelas produções dos alunos, a verificação das hipóteses que, de modo geral, teve como foco analisar se a articulação do ambiente dinâmico GeoGebra com a Geometria favoreceu a mobilização das atividades cognitivas propostas por Raymond Duval.

No presente artigo serão apresentadas as análises de duas das treze atividades aplicadas aos sujeitos no decorrer da Oficina.

A atividade que se apresenta nesse trabalho foi chamada de polígonos regulares e não regulares. Nessa atividade, eram apresentados três itens na interface do GeoGebra. Ao clicar em cada item, eram exibidos, respectivamente, 2 triângulos, 3 quadriláteros e 2 pentágonos. A figura 8 a seguir, mostra a interface dessa atividade:

Figura 8: Interface da atividade sobre polígonos regulares e não regulares

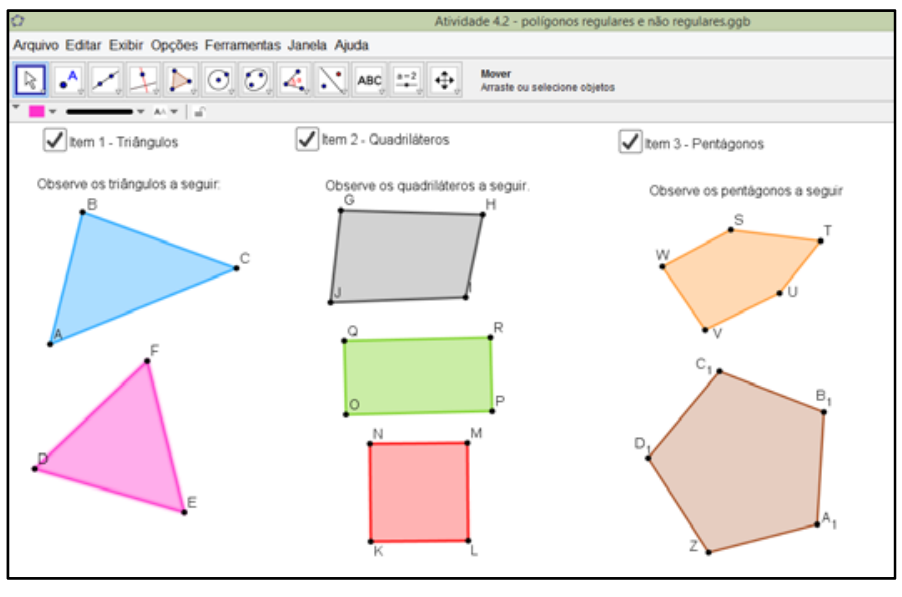

Fonte: As autoras

Foram entregues de maneira impressa instruções para o uso de ferramentas de medida de comprimento dos lados e também para a medida dos ângulos internos das figuras. Após a movimentação e observação de cada grupo de polígonos, os alunos registravam por escrito suas conjecturas.

O primeiro direcionamento da atividade foi que os sujeitos efetuassem as medidas dos lados e movimentassem os polígonos. A pretensão foi a de que visualizassem que, dentre os polígonos, um de cada formato, mesmo quando movimentado os vértices, permanecia com as medidas dos lados todas iguais.

As questões elaboradas, a partir dessa atividade, tratavam de características e diferenças observadas em relação às medidas dos lados e ângulos, após a movimentação de cada polígono. Por fim, foi questionado sobre quais figuras tratavam-se de polígonos regulares e quais características esses polígonos possuíam.

No Quadro 1 da página a seguir, a análise referente às três primeiras questões é apresentada: 
Quadro 1: Análise da atividade polígonos regulares e não regulares: conjecturas sobre a medida de lados

\begin{tabular}{|c|c|c|c|c|c|c|c|c|c|}
\hline \multirow{3}{*}{$\begin{array}{l}\text { Enunciado da } \\
\text { questão }\end{array}$} & \multirow{3}{*}{ Respostas apresentadas } & \multirow{3}{*}{ Duplas } & \multirow{3}{*}{ D.D.3 } & \multicolumn{6}{|c|}{ Apreensões 4} \\
\hline & & & & \multirow{2}{*}{ P. } & \multirow{2}{*}{ D. } & \multirow{2}{*}{ S. } & \multicolumn{3}{|c|}{ o. } \\
\hline & & & & & & & Mer. & Otc. & Pos. \\
\hline \multirow{3}{*}{$\begin{array}{l}\text { Quais diferenças você } \\
\text { percebe entre os } \\
\text { triângulos? Que } \\
\text { alterações ocorrem nas } \\
\text { medidas dos lados dos } \\
\text { triângulos? }\end{array}$} & $\begin{array}{l}\text { As medidas mudam, mas } \\
\text { o formato é o mesmo. }\end{array}$ & $\begin{array}{l}\text { A1, A7, } \\
\text { A8, B1, } \\
\text { B4 e B6 }\end{array}$ & $\mathrm{X}$ & $\mathrm{X}$ & $\mathrm{X}$ & $\mathrm{X}$ & & $\mathrm{X}$ & $\mathrm{X}$ \\
\hline & $\begin{array}{l}\text { Um dos triângulos tem as } \\
\text { medidas dos lados } \\
\text { alteradas e o outro não }\end{array}$ & $\begin{array}{l}\text { A4, A5, } \\
\text { A6, A9, } \\
\text { B2, B3 e } \\
\text { B5 }\end{array}$ & $\mathrm{X}$ & $\mathrm{X}$ & $\mathrm{X}$ & $\mathrm{X}$ & & $\mathrm{X}$ & $\mathrm{X}$ \\
\hline & Outros & $\mathrm{A} 2, \mathrm{~A} 3$ & & $\mathrm{X}$ & & X & & X & $X$ \\
\hline \multirow{3}{*}{$\begin{array}{l}\text { Quais diferenças você } \\
\text { percebe entre cada } \\
\text { quadrilátero? Que } \\
\text { alterações ocorrem nas } \\
\text { medidas dos lados dos } \\
\text { quadriláteros? }\end{array}$} & $\begin{array}{l}\text { As medidas mudam, mas } \\
\text { o formato é o mesmo }\end{array}$ & $\begin{array}{l}\text { A1, A2, } \\
\text { A3, A6, } \\
\text { A7, A8, } \\
\text { A9, B1, } \\
\text { B2 e B4 }\end{array}$ & $\mathrm{X}$ & $\mathrm{X}$ & $\mathrm{X}$ & X & & $\mathrm{X}$ & $\mathrm{X}$ \\
\hline & $\begin{array}{l}\text { O primeiro quadrilátero } \\
\text { possui medidas } \\
\text { diferentes, o segundo } \\
\text { quadrilátero possui as } \\
\text { medidas dos lados } \\
\text { opostos iguais e o } \\
\text { terceiro quadrilátero não } \\
\text { tem alteração nas } \\
\text { medidas } \\
\end{array}$ & $\begin{array}{l}\text { A4, A5, } \\
\text { B3, B5 e } \\
\text { B7 }\end{array}$ & $\mathrm{X}$ & $\mathrm{X}$ & $\mathrm{X}$ & $\mathrm{X}$ & & $\mathrm{X}$ & $\mathrm{X}$ \\
\hline & Outros & B6 & & $\mathrm{X}$ & & $\mathrm{X}$ & & X & $\mathrm{X}$ \\
\hline \multirow{3}{*}{$\begin{array}{l}\text { Quais diferenças você } \\
\text { percebe entre os } \\
\text { pentágonos? Que } \\
\text { alterações ocorrem nas } \\
\text { medidas dos lados dos } \\
\text { pentágonos? }\end{array}$} & $\begin{array}{l}\text { As medidas mudam, mas } \\
\text { o formato é o mesmo }\end{array}$ & $\begin{array}{l}\text { A1, A2, } \\
\text { A7, A8, } \\
\text { B2, B4, } \\
\text { B6 e B7 }\end{array}$ & $\mathrm{X}$ & $\mathrm{X}$ & $\mathrm{X}$ & $\mathrm{X}$ & & $\mathrm{X}$ & $\mathrm{X}$ \\
\hline & $\begin{array}{c}\text { o primeiro pentágono } \\
\text { possui medidas } \\
\text { diferentes e o segundo as } \\
\text { medidas são iguais }\end{array}$ & $\begin{array}{l}\text { A4, A5, } \\
\text { A6, B1, } \\
\text { B3 e B5 }\end{array}$ & $\mathrm{X}$ & $\mathrm{X}$ & $\mathrm{X}$ & $\mathrm{X}$ & & $\mathrm{X}$ & $X$ \\
\hline & Outros & A3 e A9 & & $X$ & & $X$ & & $\mathrm{X}$ & $X$ \\
\hline
\end{tabular}

Fonte: As autoras

As categorias de respostas referentes a cada polígono apresentado na atividade foram as mesmas. A primeira categoria, tanto para o triângulo e o quadrado, quanto para o pentágono, foi referente às respostas que indicavam a compreensão de que as medidas dos lados das figuras mudavam quando movimentadas. A dupla A1, por exemplo, foi caracterizada nesse primeiro grupo,

${ }^{3}$ D. D. Desconstrução Dimensional.

${ }^{4}$ Os nomes das apreensões foram abreviados para facilitar a disposição dos dados: P refere-se à apreensão perceptiva, D à apreensão discursiva, O para apreensão operatória e S para a apreensão sequencial. As modificações, referentes à apreensão operatória também foram abreviadas, de modo que Mer refere-se à modificação mereológica, Otc modificação ótica e Pos. para modificação posicional. 
pois escreveu "A[s] medidas dos triângulos mudam toda vez que movemos as figuras. Porque a cada vez que movemos as figuras os lados aumentam ou diminuem mudando assim as medidas."

A segunda categoria de respostas compreendeu conjecturas de que dentre as figuras após serem movimentadas, ao menos uma de cada formato mantinha as mesmas medidas para todos os lados. Por exemplo, a dupla A5 escreveu sobre os quadriláteros: "O $1^{\circ}$ quadrilátero muda totalmente o tamanho de seus segmentos de reta, após o movimento. O $2^{\circ}$ muda o tamanho, mas as linhas posicionadas de frente uma com a outra tem a mesma medida. O $3^{\circ}$ é um polígono regular, pois seus lados continuam com a mesma medida.” É possível inferir que essa dupla já reconheceu, dentre os quadriláteros, que um deles era regular, quando escreveu sobre conjecturas referentes ao $3^{\circ}$ polígono exibido na tela do GeoGebra.

Por fim, foi estabelecido um terceiro grupo de respostas, chamado de outras, o qual contemplou respostas incompreensíveis sem a possibilidade de relação com as categorias anteriores e também as respostas em branco.

Foram verificadas que as apreensões sequencial, perceptiva, discursiva e operatória com modificações ótica e posicional foram mobilizadas. Por meio da verificação dos arquivos digitais, se observou que a sequência de instruções para obtenção das medidas dos lados foi seguida corretamente pelas duplas, caracterizando a apreensão sequencial. As apreensões perceptiva e discursiva foram necessárias, pois, pela apreensão perceptiva, o reconhecimento das figuras era imediato e a presença de um discurso guiava o olhar sobre as figuras.

A apreensão operatória com modificação ótica foi estabelecida por meio do movimento dos polígonos. A dupla A8, caracterizada no grupo de respostas: as medidas mudam, mas o formato é o mesmo, menciona sobre os quadriláteros que: "A numeração mudou, mas não houve mudança no formato." Quando a dupla escreveu a palavra "numeração”, é possível inferir que se refere às medidas dos lados dos quadriláteros. A dupla A1 conjecturou que as medidas dos triângulos mudavam: "Porque a cada vez que movemos as figuras os lados aumentam ou diminuem mudando assim as medidas." Tanto as respostas de A1 quanto de A8 indicaram que a modificação ótica esteve presente. De acordo com Duval (2012b), nesse tipo de modificação a figura é aumentada, diminuída ou deformada. No entanto, é possível inferir que, além da modificação ótica, outro tipo de modificação se fez presente com o uso do GeoGebra.

A figura que recebe uma modificação posicional, segundo Duval (2012a, p. 126), "pode-se deslocá-la ou rotacioná-la em relação às referências do campo onde ela se destaca”. Quando a dupla B5 (grifos nossos) escreveu sobre o quadrado que "[...] no KLMN ao movimentar um vértice a figura gira e a medida fica igual”, compreendeu-se que a modificação posicional também esteve presente.

Ao propor a retomada do conceito de polígono regular com essa atividade, restava ainda a medida dos ângulos, pois, segundo Souza e Pataro (2015) além da medida dos lados, os ângulos internos e externos também possuem medidas iguais. Para obter a medida dos ângulos, uma sequência de três passos precisava ser seguida para cada um dos polígonos, conforme ilustra o quadro a seguir:

Quadro 2 - Passo-a-passo para a obtenção da medida dos ângulos na atividade 4.2

1- Selecione a ferramenta Ângulo $\longleftarrow$ e no sentido horário clique sobre os vértices A, B e C do triângulo da cor azul. O GeoGebra exibirá a medida do ângulo $A \widehat{B} C$.

2- Proceda da mesma maneira para todos os ângulos internos de cada um dos triângulos.

\section{3- Clique na ferramenta mover}


Depois de movimentarem os polígonos, outras três questões foram respondidas. Essas questões eram sobre quais diferenças tinham observado em relação às medidas dos ângulos nos triângulos, quadriláteros e pentágonos.

A partir dessas questões, três categorias de respostas foram frequentes. A primeira categoria se referiu a conjecturas corretas de sete duplas (A1, A5, A8, A9, B1, B4 e B5) de que, dentre os polígonos, pelo menos um possuía ângulos iguais. Por exemplo, a resposta da dupla A9 sobre a medida dos ângulos dos triângulos, em que "O primeiro triângulo mexe o ângulo e o segundo não mexe.” indicou uma percepção coerente.

Sobre os pentágonos, a dupla A1 escreveu "Eles [são] como os triângulos, os ângulos também aumentam e diminuem, e um dos pentágonos as medidas dos ângulos não mudam.” A dupla A1, quando respondeu que observou que um dos pentágonos presentes na atividade não tinha alterações na medida dos ângulos, foi caracterizada também no grupo de respostas: a medida dos ângulos de um dos pentágonos não muda.

A segunda categoria de respostas reuniu conjecturas de cinco duplas (A2, A6, B2, B6 e B7): as medidas dos ângulos mudam, foi comum a todos os polígonos, compreendeu as conjecturas que indicaram somente a mudança dos ângulos sem mencionar que, dentre eles, pelo menos um não tinha as medidas dos ângulos alteradas. A dupla A2, por exemplo, escreveu para todas as questões elaboradas que os ângulos dos polígonos "mudam de acordo com a movimentação.” Outra dupla, A6, também escreveu a mesma resposta para todas as questões, de que "os ângulos mudam sua numeração de graus."

Os questionamentos feitos, a partir da medida dos ângulos dos polígonos contidos nessa atividade, contemplaram as apreensões perceptiva, discursiva, sequencial e operatória, com modificações ótica e posicional. Exceto para uma dupla A5, que escreveu a respeito dos triângulos que o "Triângulo Rosa - É um polígono regular, seus ângulos não mudam.” Nessa parte da atividade, compreendeu-se que não foi mobilizada a desconstrução dimensional, pois se trabalhou unicamente na dimensão 2.

Para finalizar, foram propostas outras questões com respostas escritas sobre quais polígonos eram regulares e quais características lhes poderiam ser atribuídas. A respeito das características que esses polígonos possuíam, outras quatro recorrências de respostas emergiram. A primeira categoria, chamada de Todos os lados e ângulos iguais, contemplou as respostas corretas dadas pelas duplas (A3, A4, A5, A7, B5 e B6), ao mencionarem as duas características dos polígonos regulares. A segunda e terceira categorias de respostas, respectivamente, contemplaram respostas que mencionaram ou somente que os ângulos eram idênticos ou então que os lados eram iguais quando se tratava dos polígonos regulares.

Em relação à segunda recorrência, chamada de: todos os ângulos iguais, dentre as duplas A1, A6, A9, B4 e B7, três delas conjecturaram, respectivamente, que: "os polígonos regulares não há alterações nos ângulos”, "que o triângulo só chega a $60^{\circ}$ o quadrilátero a $90^{\circ}$ e o pentágono a $108^{\circ}$ mais só soube isso por causa da ferramenta ângulo" e que "eles não mudam seus ângulos.” Despertou interesse nas respostas dadas por essas duplas, pois, quando se referiram aos quadriláteros, mencionaram que eram regulares tanto o quadrado quanto o retângulo.

Pela observação dos arquivos digitais, constatou-se que as duplas conseguiram estabelecer as medidas dos lados em todos os polígonos contidos na atividade. No entanto, quando não mencionaram que os lados de um polígono regular também possuem a mesma medida, caracterizaram um indicativo de que não houve a desconstrução dimensional de 2D 1D.

Segundo Duval (2011), a mudança de uma dimensão a outra é contrária ao reconhecimento imediato das formas, porque a unidade figural da dimensão superior se impõe de modo imediato à percepção. Os sujeitos que consideraram somente características dos polígonos regulares, referente aos ângulos iguais, permaneceram na dimensão dois, sem voltar o olhar para os lados dos polígonos que estão na dimensão inferior. Isso levou ao equívoco de mencionarem o retângulo como um polígono 
regular. Não obstante este fato, a resposta, por exemplo, da dupla A3 que "só soube isso por causa da ferramenta ângulo" denotou a potencialidade do uso do software GeoGebra. Por meio do movimento das figuras, a percepção é aguçada, facilitando conjecturas.

Por fim, um quarto grupo de respostas, chamado de outras, contemplou respostas incoerentes (B1 e B2), a exemplo do caso do sujeito B1, que citou como característica dos polígonos regulares "que eles não se cruzam”. A resposta dada por B1 de que os polígonos vistos na atividade não se cruzam foi uma das características trabalhadas em aulas anteriores da oficina sobre as diferenças entre um polígono e um não polígono.

A atividade, sob um ponto de vista cognitivo, mobilizou as quatro apreensões. A apreensão perceptiva e discursiva para interpretação dos polígonos esteve presente na interface do GeoGebra. Conforme Duval (2004, p. 168, tradução nossa) menciona: “não há desenho sem legenda.” Nessa atividade, as figuras receberam uma designação por meio de letras maiúsculas, e, por meio dos enunciados, eram fornecidos os dados para serem considerados sobre as figuras. A apreensão sequencial que implicava o seguimento correto das instruções para a obtenção das medidas dos ângulos também foi mobilizada.

Outras respostas a respeito das características dos polígonos regulares confirmaram o pressuposto da análise preliminar feita por Novak (2018) sobre a desconstrução dimensional que poderia estar presente nessa atividade. Quando se questionou sobre as características dos polígonos regulares, algumas duplas A5, A7, B5 responderam, respectivamente, que os polígonos regulares possuem "ângulos do mesmo tamanho, segmentos de reta do mesmo tamanho", "todos tem lados do mesmo tamanho (os lados) e o mesmo tamanho de ângulos", "tem as medidas dos lados e dos ângulos iguais", e, por fim, um sujeito que realizou as atividades sozinho, B7 escreveu que "os lados são todos iguais e os ângulos internos”. Ao mencionarem sobre as características observadas nos lados dos polígonos, compreendeu-se que uma desconstrução dimensional de 2D 1D foi estabelecida, pois dos polígonos (2D) os olhares se voltaram para os lados (1D).

Outra atividade consistia na construção de cada poliedro regular no GeoGebra em arquivos distintos a partir de instruções dadas por impresso. Pelo quadro a seguir, são mostradas como exemplo, as instruções de construção do dodecaedro:

Quadro 3 - Instruções de construção do dodecaedro na atividade 6.0

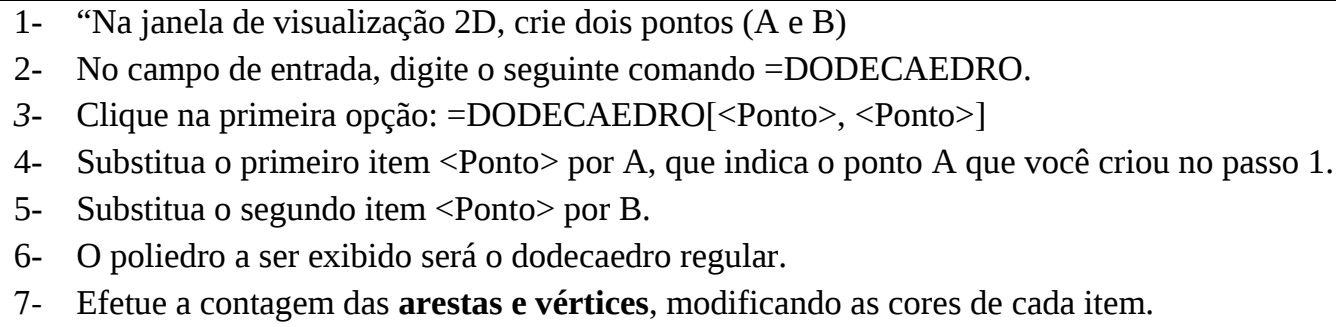

Fonte: Novak, 2018, p. 117

Quanto ao seguimento das instruções de construção dos cinco poliedros regulares, os sujeitos não apresentaram dificuldades. As instruções de construção caracterizaram a apreensão sequencial, enquanto que a designação de elementos dessas instruções, como as palavras: pontos, arestas e vértices compreenderam uma apreensão discursiva, pois os alunos precisavam compreender o significado dessas palavras para conferirem se o que aparecia construído na tela do GeoGebra era condizente com o que se pedia.

Partindo desse pressuposto, não se pode deixar de mencionar que a apreensão perceptiva também foi presente, pois a cada passo da construção era necessário o reconhecimento automático dos formatos que apareciam na tela. Outra apreensão presente foi a apreensão operatória com modificações ótica e posicional. Os alunos arrastavam os poliedros e podiam aumentá-los ou diminui- 
los para conseguirem estabelecer quantas arestas, vértices e faces possuíam. Ao voltarem-se para esses elementos, foi presente a desconstrução dimensional na realização dessa atividade.

Quando apresentada a ferramenta de planificação, a presença da desconstrução dimensional de 3D 2D foi estimulada. A partir da construção do poliedro, ao clicar nessa ferramenta era possível, pelo arrastamento do controle deslizante, "montar e desmontar" o poliedro, facilitando a observação de suas faces.

Um destaque em relação à ferramenta de planificação do GeoGebra foi registrado em áudio e transcrito no quadro a seguir:

Quadro 4 - Diálogo sobre a ferramenta de planificação

\begin{tabular}{|l|l|}
\hline Trecho do diálogo da pesquisadora com o G2 & Interface do GeoGebra que se refere ao diálogo \\
\hline Pesquisadora - Aí quando vocês forem contar o \\
púme daces, tem aqui uma ferramenta chamada \\
consegue ver? \\
Alunos - si:::m: \\
Pesquisadora - Vocês vão clicar sobre ela e vão \\
clicar sobre o tetraedro. O que que aconteceu? \\
Um aluno de B4 - Meu Deus. Umas coisas. \\
Pesquisadora - Apareceu a planificação do tetraedro \\
e apareceu essa outra ferramenta que se chama \\
controle deslizante. O que vocês vão fazer com ela, \\
vão vir aqui e vão movimentar esse controle \\
deslizante. \\
Um aluno de B5 - nooossa que legal. \\
Vários alunos - oohhh \\
Um dos alunos de B3 - nossa que massa
\end{tabular}

Fonte: Novak, 2018, p. 115

Como é possível observar pelo Quadro 29, na interface do GeoGebra, na janela de visualização 2D, é exibido o formato da face que está sobre o plano na cor cinza na janela 3D. Situação essa que favorece a desconstrução dimensional e pode ser explorada de diferentes maneiras pelo professor. É possível verificar que mesmo tendo os primeiros contatos com o software, as falas dos alunos evidenciaram entusiasmo com o uso do ambiente dinâmico.

\section{CONSIDERAÇÕES FINAIS}

As possibilidades de desenvolvimento de atividades em um ambiente dinâmico como o GeoGebra são vastas. Embora consista numa situação laboriosa para o professor, a partir de pressupostos teóricos que indicam aspectos relevantes a serem considerados para a aprendizagem da Geometria, como os descritos por Raymond Duval, há um melhor direcionamento sobre o que melhor se adequa a cada conteúdo escolhido.

As questões apresentadas nesse trabalho envolveram a análise de características dos polígonos regulares e não regulares, bem como a construção dos poliedros regulares e suas planificações. Essas atividades mostraram estimular a desconstrução dimensional. Com a facilidade em manipular as figuras, como no caso dos polígonos, os alunos puderam observar de maneira dinâmica o comportamento dos segmentos, por meio do arrastamento dos vértices e dos ângulos, o que evidenciou a desconstrução dimensional de $2 \mathrm{D} \rightarrow 1 \mathrm{D} \rightarrow 0 \mathrm{D} \rightarrow 2 \mathrm{D}$. O mesmo fato pode ser observado quando os alunos trabalharam com os poliedros. A atenção voltou-se para o formato das faces e para as arestas. A desconstrução dimensional foi presente, pois, de modo geral, as atividades elencavam a necessidade de observar as unidades figurais inferiores as da figura mostrada na interface do GeoGebra. 
Outro aspecto a considerar é em relação a possibilidade de movimento das figuras geométricas. Ao serem movimentadas de modo imediato, a mobilização da apreensão operatória foi presente com as modificações ótica e posicional de modo simultâneo, o que diferenciou de uma exploração em um ambiente estático, em que esse tipo de ação demandaria um custo de tempo elevado.

O uso do software GeoGebra permitiu estímulo da apreensão perceptiva. As figuras geométricas, por meio do movimento, assumiam posições não canônicas. Todas as atividades propostas estavam acompanhadas de enunciados, presentes tanto na interface do GeoGebra quanto no material impresso que foi entregue para cada dupla. A compreensão e realização de maneira correta ou parcialmente correta das atividades indicou que a apreensão discursiva também foi mobilizada.

Ao conferirem as medidas dos lados e dos ângulos dos polígonos e, em seguida, ao movimentar, arrastar ou girar cada figura foi proporcionado direcionamento para que os alunos verificassem que as propriedades geométricas, em especial, na atividade sobre os polígonos regulares e não regulares eram mantidas.

O seguimento de instruções de construção de figuras geométricas, exemplificados na segunda atividade é resgatado de maneira singular. É necessário tanto o conhecimento de termos matemáticos como reta, ponto, aresta, quanto o conhecimento das ferramentas que permitem determinada construção. O painel de comandos do GeoGebra é intuitivo, pois apresenta seus ícones por meio de desenhos seguidos de pequenas indicações dos que pode ser obtido. A partir disso, para as atividades em que os alunos precisaram seguir instruções de construção no GeoGebra, não foram verificadas dificuldades. O que precisa ser levado em conta é que essas facilidades de construção não devem omitir compreensões necessárias a respeito das figuras geométricas.

Com o uso desse software, é possível que explorações dos conteúdos matemáticos, bem como dos pressupostos teóricos de Raymond Duval, sejam eficientes. Como sugestão, poderão ser propostas em pesquisas futuras, atividades em que a apreensão operatória com modificação mereológica sejam elaboradas, bem como explorações mais aprofundadas com mobilização da desconstrução dimensional para a resolução de problemas de geometria envolvendo o papel heurístico das figuras geométricas.

\section{REFERÊNCIAS}

ANDRINI, A; VASCONCELlOS, J. M. Praticando matemática. São Paulo: Editora do Brasil, 2012.

BARDIN, L. Análise de conteúdo. Lisboa: Edições 70, 2016.

BRASIL. Secretaria de Educação. Parâmetros Curriculares Nacionais: Ensino Fundamental Matemática. Brasília: MEC/SEF, 1998. 148 p.

DUVAL, R. Abordagem cognitiva de problemas de geometria em termos de congruência. Tradução: Méricles Thadeu Moretti. Revemat, Florianópolis, v. 7, n. 1, p. 118-138, jan./jun. 2012a. Disponível em: https://periodicos.ufsc.br/index.php/revemat/article/view/1981-1322.2012v7n1p118. Acesso em: 28 jan. 2017.

DUVAL, R. Registros de representação semiótica e funcionamento cognitivo do pensamento. Tradução: Méricles Thadeu Moretti. Revemat, Florianópolis, v. 7, n. 2, p. 266-297, jul./dez. 2012b. Disponível em: https://periodicos.ufsc.br/index.php/revemat/article/view/19811322.2012v7n2p266/23465. Acesso em: 27 jan. 2017

DUVAL, R. Ver e ensinar a matemática de outra forma: entrar no modo matemático de pensar os registros de representações semióticas. São Paulo: PROEM, 2011.

DUVAL, R. Les conditions cognitives de l'apprentissage de la géométrie: développement de la visualisation, différenciation des raisonnements et coordination de leurs fonctionnements. In.: 
PLUVinAGE, F. (dir.). Annales de Didactique et Sciences Cognitives, v. 10. Strasbourg: IREM, 2005. p. 5-53. Disponível em: http://www.irem.univ-parisdiderot.fr/up/annales_de_didactique_et_de_sciences_cognitives/volume_10/Duval.pdf. Acesso em: 01 fev. 2017.

DUVAL, R. Semiosis y pensamiento humano: registros semióticos y aprendizajes intelectuales. Santiago de Cali: Peter Lang, 2004.

GRAVINA, M. A. E. et al. Geometria dinâmica na escola. In.: GRAVINA, M. A. E. et al. (orgs.). Matemática, mídias digitais e didática: tripé para formação de professores de Matemática. Porto Alegre: UFRGS, 2010. p. 37-60 Disponível em: <http://www.ufrgs.br/espmat >. Acesso em: 01 abr. 2017.

LORENZATO, S. A. Por que não ensinar Geometria? A Educação Matemática em Revista, São Paulo, v. 4, p. 3-13, jan./jun. 1995.

MORETTI, M. T.; BRANDT, C. F. Construção de um desenho metodológico de análise semiótica e cognitiva de problemas de geometria que envolvem figuras. Educação Matemática Pesquisa, São Paulo, v. 17, n. 3, p. 597-616, nov. 2015. Disponível em: <http://revistas.pucsp.br/index.php/emp/article/view/25673>. Acesso em: 01 fev. 2017.

NOVAK, F. I. L. O ambiente dinâmico GeoGebra para o desenvolvimento de aspectos específicos da aprendizagem em geometria segundo Raymond Duval: olhares, apreensões e desconstrução dimensional. 2018. 149 f. Dissertação (Mestrado em Educação) - Programa de Pós-Graduação em Educação, Universidade Estadual de Ponta Grossa, Ponta Grossa, 2018.

PONTE, J. P. Estudos de caso em educação matemática. Boletim de Educação Matemática (BOLEMA), São Paulo, v. 19, n. 25, p. 1-23, jan./jun. 2006. Disponível em: http://www.periodicos.rc.biblioteca.unesp.br/index.php/bolema/article/view/1880/1657. Acesso em: 04 out. 2017.

SCHEIFER, C. Design Metodológico para análise de atividades de geometria segundo a Teoria dos Registros de Representação Semiótica. 2017. 148 f. Dissertação (Mestrado em Educação) Programa de Pós-Graduação em Educação, Universidade Estadual de Ponta Grossa, Ponta Grossa, 2017.

SOUZA, J.; PATARO P. M. Vontade de saber matemática, 6º ano. São Paulo: FTD, 2015. p. 180. 